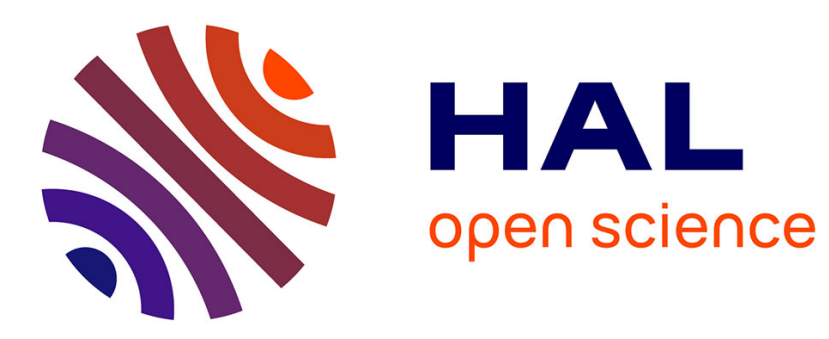

\title{
Study of passive control study of the cavitation instability on a venturi profile
}

Amélie Danlos, Florent Ravelet, Christophe Sarraf, Jean-Hélie Mehal

\section{To cite this version:}

Amélie Danlos, Florent Ravelet, Christophe Sarraf, Jean-Hélie Mehal. Study of passive control study of the cavitation instability on a venturi profile. 8th International Symposium on Cavitation (Cav2012), Aug 2012, Singapore, Singapore. pp.N 240. hal-00707388

\section{HAL Id: hal-00707388 \\ https://hal.science/hal-00707388}

Submitted on 12 Jun 2012

HAL is a multi-disciplinary open access archive for the deposit and dissemination of scientific research documents, whether they are published or not. The documents may come from teaching and research institutions in France or abroad, or from public or private research centers.
L'archive ouverte pluridisciplinaire HAL, est destinée au dépôt et à la diffusion de documents scientifiques de niveau recherche, publiés ou non, émanant des établissements d'enseignement et de recherche français ou étrangers, des laboratoires publics ou privés. 


\section{STUDY OF PASSIVE CONTROL STUDY OF THE CAVITATION INSTABILITY ON A VENTURI PROFILE}

\author{
Amélie Danlos \\ Laboratoire de Dynamique des Fluides (DynFluid) \\ Arts et Métiers ParisTech, EA 92, France \\ Christophe Sarraf \\ Laboratoire de Dynamique des Fluides (DynFluid) \\ Arts et Métiers ParisTech, EA 92, France
}

\author{
Jean-Elie Mehal \\ Laboratoire de Dynamique des Fluides (DynFluid) \\ Arts et Métiers ParisTech, EA 92, France \\ Florent Ravelet \\ Laboratoire de Dynamique des Fluides (DynFluid) \\ Arts et Métiers ParisTech, EA 92, France
}

\section{SUMMARY}

As a source of vibrations, noise, erosion and structure damages, cavitation is a major handicap for many industrial flows used in different domains from propeller or pump studies, to the analysis of hydrodynamic flows around a profile. This work presents results of the effect of a passive control method, based on surface roughness, on a venturi profile in order to determine how to reduce or even suppress cloud cavitation developed on its suction side. Visualizations and velocity measurements permit to detect the influence of roughness on flow development. So as to have a better understanding of flow dynamics of sheet and cloud cavitation, robust mathematical methods of imaging post-processing have been used like Proper Orthogonal Decomposition.

\section{INTRODUCTION}

Cavitation is a crucial parameter in the design of turbomachinery like turbopumps or liquid propellers. Indeed this phenomenon causes vibrations, noise and even erosion and destruction of device solid components. These damages have to be avoided and many studies have been already conducted in cavitation tunnels in order to understand this phenomenon. Many authors worked on the problem of cavity occurence but rarely on fully developed cavitating flows. This case is yet a common event in many industrial flows, especially in liquid flows which present a high acceleration induced by a fixed or moving body. Simple geometries like 2D foil sections, or Venturi type sections are used to approach sheet cavitation dynamics. The present study is going to determine new ways to control sheet cavitation and its consequences on the flow for an improvement of the machinery efficiency and a reduction of solid damages of structures in the case of a Venturi type section in a water tunnel.

Sheet cavity is submitted to quasi-periodical fluctuations which create a well-known cycle ( [1-5]): sheet cavity grows from the venturi throat. A re-entrant jet is generated at the leading edge of the cavity and moved upstream. When this re-entrant jet reaches the interface at the cavity closure, a cloud convection appears with the shedding of a great vapour cloud convected downstream. Then cloud cavitation collapses in a higher pressure region and sustains the re-entrant jet due to cloud implosion and produced a new shedding of cavitation cloud. This life cavity cycle is characterized by the shedding frequency $f$. This frequency is then a witness of cavity instabilities. Vibrations are an handicap for many industrial applications, as for inducers ( [6-8]).

Some studies have been conducted to delay cavitation inception by modifying foil surface rugosity using local protuberances with different geometries or distributed roughness (Arndt 1981 [9], Arndt and Ippen (1968) [10]). This modification acts on the turbulent boundary layer which drives sheet cavitation. In many industrial applications, the cavitation effect on surface drag is also an important parameter. It needs a better understanding not only of the cavitation inception and development but also of the sheet cavities distribution and stability. Rare works exist about the role of rugosities in a fully developed cavitating flow. Some studies show that roughness is able to decrease sheet cavity length and to increase oscillation frequency of the cavity (Coutier-Delgosha 2005 [11], Stutz 2003 [12]). The roughness distribution and geometry is a major characteristic of this passive control method of cavitation: tranversal or longitudinal grooves, with smooth or straight edges, for different depths or interval lengths gives various results on sheet cavitation dynamics (Yongjian et al. 2010 [13]).

The present study deals with the influence of longitudinal grooves and the geometry of this distributed roughness on sheet cavitation dynamics. In order to analyze images of the flow, robust mathematical post-processing methods such as Proper Orthogonal Decomposition (Holmes et al. 1996 [14]). 


\section{EXPERIMENTAL SETUP}

\section{Test section}

Experiments were performed in the Dynfluid laboratory water tunnel. The closed loop test rig is composed of two linked storage tanks with a capacity of $4 \mathrm{~m}^{3}$ each. A vacuum pump can decrease pressure at the free surface of tanks, in order to decrease pressure in the test rig. A centrifugal pump which can turn up to $1450 \mathrm{tr}_{\mathrm{min}}^{-1}$ induces a $240 \mathrm{~m}^{3} \cdot \mathrm{s}^{-1}$ flowrate for a Reynolds Number $R e_{\text {throat }}=V_{\text {throat }} H_{\text {thorat }} / v=5.510^{5}$ where $V_{\text {throat }}$ is the velocity and $H_{\text {throat }}$ the height of the tunnel at the venturi throat, for a water flow, with the viscosity $v$. Upstream of the test section (figure 1) the water tunnel has a series of flow management screens (honeycombs) followed by a circular contraction for a velocity top hat profile of the flow upstream the venturi (less than $1 \%$ of turbulence intensity at the test section inlet). The test section has four plexiglas windows permitting $3 \mathrm{D}$ visualization measurements of the flow induced by a venturi with $18^{\circ}$ and $8^{\circ}$ convergent and divergent angles respectively. Venturi surface is smooth but grooved brass sheets can be screwed on the venturi type suction side to study the effects of roughness on cavitation dynamics. These grooved sheets (figure 2) are characterized by the the groove diameter, its depth and the spacing between two grooves (for example, the "8-1.2-0.045" grooved sheet presents a $8 \mathrm{~mm}$ groove diameter, its depth is equal to $1.2 \mathrm{~mm}$ and a spacing of $0.045 \mathrm{~mm}$ separates two grooves).

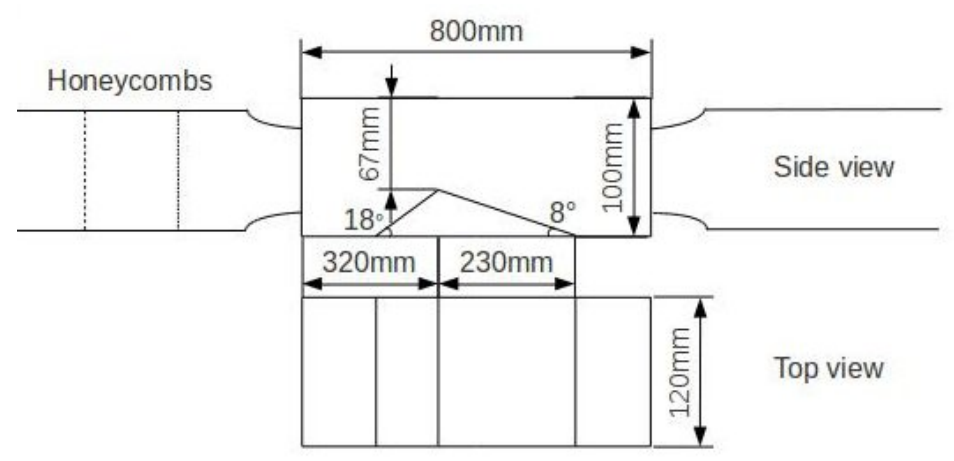

Figure 1. Venturi type test section

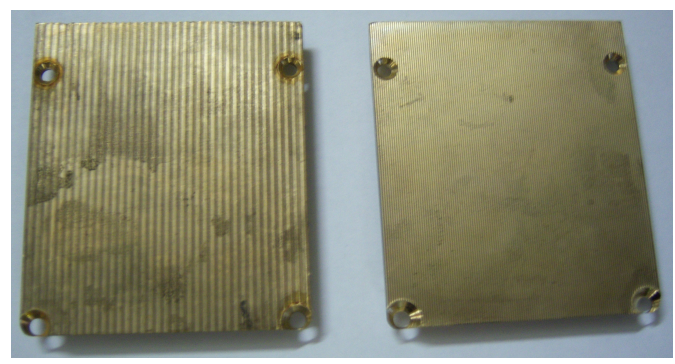

Figure 2. Examples of grooved brass sheets

\section{Visualization measurements}

Visualization measurements are conducted for different roughness and different cavitation numbers $\sigma=\left(p_{\text {ref }}-p_{\text {vap }}\right) /\left(\frac{1}{2} \rho v_{r e f}^{2}\right)$ (from 0.9 to 1.7 ) in order to compare results with the smooth reference case. $p_{v a p}$ is the vapor pressure at temperature $T=293 K$ (temperature deviation during measurements is small enough to neglect temperature effect on results) of the fluid with the density $\rho, p_{r e f}$ and $v_{r e f}$ are respectively the pressure and the velocity upstream the venturi profile. 4000 images are acquired for each configuration (for a given cavitation number and a given grooved sheet geometry) with a CamRecord 600 Optronics camera using a Zeiss Makro-planar $\mathrm{T}^{*}$ with a focal length equal to $100 \mathrm{~mm}$. This high-speed CMOS camera records images with a $1280 \times 512$ pixels $^{2}$ resolution, a rate of 1000fps and an exposure time equal to $0.167 \mu \mathrm{s}$. The pixels size is $12 \mu \mathrm{mx} 12 \mu \mathrm{m}$ for an active area of $15.36 \mathrm{~mm} \times 12.29 \mathrm{~mm}$. The flow is illuminated by a SLLUB (Super Long Life Ultra Bright) White Led Backlight from Phlox on a $200 \mathrm{~mm} \times 200 \mathrm{~mm}$ light output area. Its luminance minimum is $30000 \mathrm{~cd} . \mathrm{m}^{-2}$ in continuous mode and its uniformity is $99.54 \%$.

Water flows in the test section with a flow rate $Q=$ $240 \mathrm{~m}^{3} \cdot \mathrm{h}^{-1}\left(v_{\text {ref }}=8 \mathrm{~m} \cdot \mathrm{s}^{-1}\right)$, for a pressure low enough to obtain a range of cavitation numbers $\sigma$ from 1 to 1.9 .

\section{PROPER ORTHOGONAL DECOMPOSITION}

Proper Orthogonal Decomposition (POD) is an efficient post-processing method used to study spatial and temporal coherent structures in a turbulent flow. This method, already tested in many other disciplines (signal analysis, image processing, data compression, oceanography...), was introduced in turbulence studies by Lumley [15] in 1967. This post-processing technique provides an optimal basis for the modal decomposition of a statistical set of functions. It captures dominant components of an infinite dimensions process with only few modes. Calculations are based on the spectral theory of compact self-adjoint operators. If we consider that $\left\{u^{k}(x)\right\}$ is a set of scalar fields defined on $0<x<1$, the aim of the POD is to find a set of optimal basis of the space of square integrable functions $L^{2}$, which describes the typical members of the set:

$$
u_{N}(x)=\sum_{j=1}^{N} a_{j} \phi_{j}(x)
$$

$\left\langle|(u, \phi)|^{2}\right\rangle$ has to be maximized with $\|\phi\|^{2}=1$, where $\langle$.$\rangle is the$ modulus and $\|$.$\| the norm in L^{2}$. A corresponding function to this variational problem is defined as:

$$
J[\phi]=\left\langle|(u, \phi)|^{2}\right\rangle-\lambda\left(\|\phi\|^{2}-1\right)
$$

Maximization for all variations $\phi+\delta \psi$ amounts then to:

$$
\frac{d}{d \delta} J[\phi+\delta \psi]_{\delta=0}=0
$$


As $\psi(x)$ is an arbitrary variation, we obtain:

$$
\int_{0}^{1}\left\langle u(x) u^{*}\left(x^{\prime}\right)\right\rangle \phi\left(x^{\prime}\right) d x^{\prime}=\lambda \phi(x)
$$

Where $R\left(x, x^{\prime}\right)=\left\langle u(x) u^{*}\left(x^{\prime}\right)\right\rangle$ is the averaged autocorrelation function. POD results in solving the eigenvalue equation:

$$
\mathscr{R} \phi=\lambda \phi
$$

The eigenfunctions obtained by this decomposition are orthonormal and the eigenvalues are all positive or null and ranked in descending order $\left(\lambda_{j}>\lambda_{j+1}>\ldots \geq 0\right)$. Each scalar field of the initial set can also be exactly reconstructed according to:

$$
u(x)=\sum_{j=1}^{\infty} a_{j} \phi_{j}(x)
$$

With $a_{j}$ the reconstruction coefficients calculated as:

$$
\left\langle a_{j} a_{k}^{*}\right\rangle=\delta_{j k} \lambda_{j}
$$

$\delta_{k j}$ being the Kroenecker symbol.

In the POD method, the eigenfunctions obtained give information on the mode shape and define the "skeleton" of the spatial or temporal coherent structure. On the other hand, the eigenvalues designate the "weight" of each mode in the reconstruction of each initial image, in order to know the significance of the coherent structure in the dynamics of the studied phenomenon.

This post-processing is used here to determine which part of the cavitating flow can be affected by roughness effects. By studying each mode resulting on the decomposition of cavitation cloud evolution images, we can deduce the mode responsible for the cloud detachment for example, and we can focus the study of the roughness effect on this analysis.

\section{RESULTS}

\section{Cavity mean length}

In order to determine the cavity mean length, mean values and standard deviation of the grey levels are calculated on the 4000 images of each studied case. The mean cavity length extends from the venturi throat to the cloud separation location. This end of the cavity is detected with the maximum value of standard deviation of grey levels, according to the method proposed by Dular et al. [4] as it is shown on figure 3 .

Figure 4 shows the evolution of the cavity mean length according to the cavitation number, for different grooved sheets, in comparison with the smooth case (red crosses). We can see that for specific roughness conditions, the mean length cavity decreases as it has been encountered in litterature (CoutierDelgosha [11]). But some roughness conditions seem to increase cavity mean length too. This difference between the effects of roughness is larger for small cavitation numbers. When $\sigma$ is

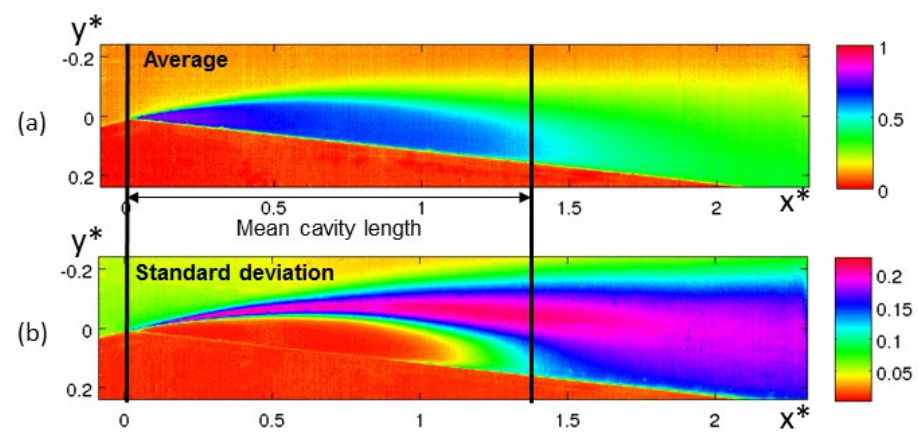

Figure 3. Mean cavity length represented on the (a) average and the (b) standard deviation of the grey levels of images in the case of smooth venturi profile, according the undimensional coordinates $x^{*}=x / h_{\text {throat }}$ and $y^{*}=y / h_{\text {throat }}$

greater than 1.2 the influence of the surface state seems to be less important on the mean cavity length evolution. For all grooved sheets, the cavitation cloud length increases with the cavitation number. But the analysis of the mean cavity length is insufficient to understand the role of roughness in sheet cavitation dynamics, and more particularly, the effect of the rugosity shape.

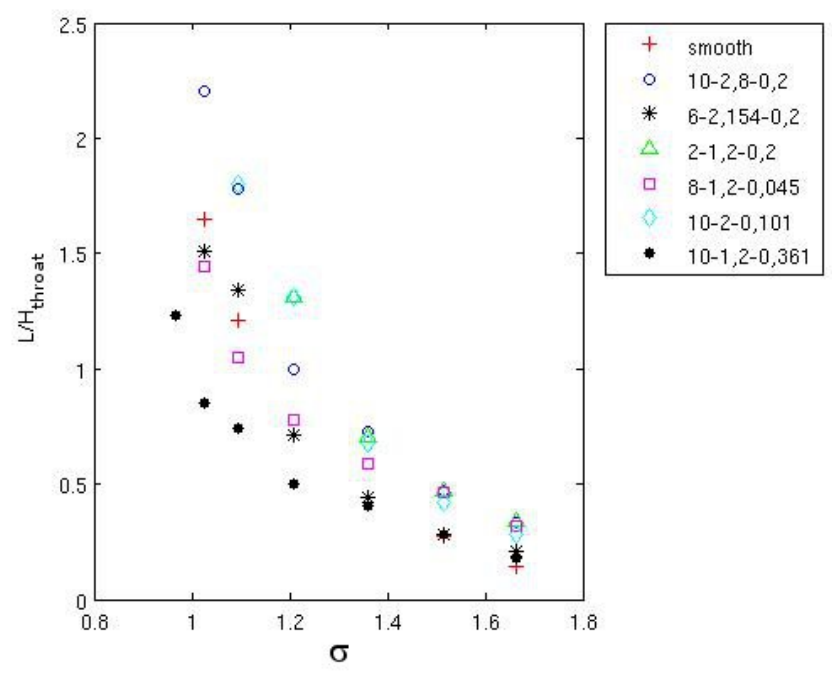

Figure 4. Dimensionless cavity mean length $L / H_{\text {throat }}$ according to the cavitation number $\sigma$ for different rugosity shapes of the venturi suction side

\section{Shedding of cloud cavitation}

The shedding of the cloud cavitation is periodical. The frequency of this shedding is determined by studying the evolution of the grey levels at the cavity closure position. The power spectral density of this grey level permit to determine the evolution of the shedding according to the mean cavity length for each studied case of venturi profile surface roughness (figure 5). Here, the frequency difference between the smooth venturi profile and the other grooved sheets is greater when the mean cavity length 
is small (it means for large cavitation numbers). In this case, this measurement is difficult if the cavitation cloud is small. It is then interesting to purchase analysis for large cavitation numbers with other shedding frequency measurement method in order to interpret results. The shedding frequency is also represented on the figure 6 with the undimensional Strouhal number $S t_{L}=L f / v_{\text {throat }}$. If we look at the smooth case, we can observe that for $1 \leq \sigma \leq 1.4$, the Strouhal number is around 0.3 , as it has been calculated on other experiments in Coutier-Delgosha et al. [11]. On the other side, for $1.4 \leq \sigma<1.8$, the Strouhal number decreases until reaching a value smaller than 0.1 . These two zones of Strouhal numbers exist for the grooved sheets. Figure 7 shows that this break of Strouhal number is in accordance with Stutz et al. [2] results: in their study, they calculate the shedding frequency according to the ratio $v_{\text {ref }} / L$. Results obtained with the smooth case of our study are superposed to Stutz et al. results in the range $100 \leq v_{r e f} / L<400$. Out of this range, Stutz et al. present no measurements but there is a break in the curve that indicatse a different behaviour of the cavitation cloud dynamics for small mean cavity length, and so for large cavitation numbers. But we can also see with figure 6 that the roughness of the venturi profile surface can modify the Strouhal number. All these observations do not permit to determine how roughness acts on the sheet cavity and on the cloud cavitation shedding. To improve the analysis of this study, we can use a POD post-processing of images recorded on the venturi profile to detect significant parameters in the cavitation cloud mechanisms.

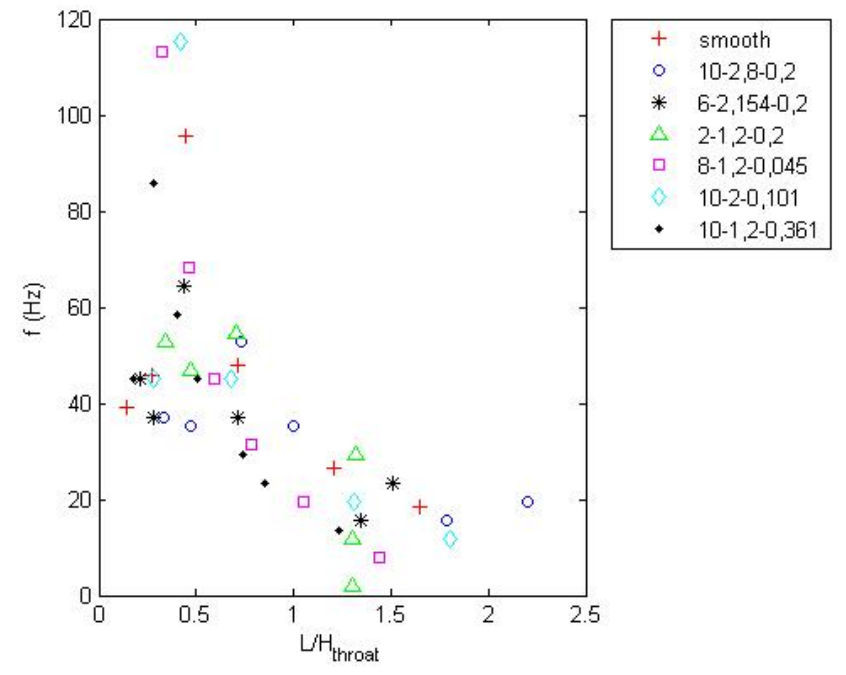

Figure 5. Frequency of cloud cavitation shedding $f$ according to dimensionless cavity mean length $L / H_{\text {throat }}$ for different rugosity shapes of the venturi suction side

\section{POD analysis of images}

For each studied case, on smooth and grooved venturi profiles, a post-processing of POD is applied on 100 images. Tests have been conducted to validate the number of frames used for the POD for each case. Results obtained for the four first modes are

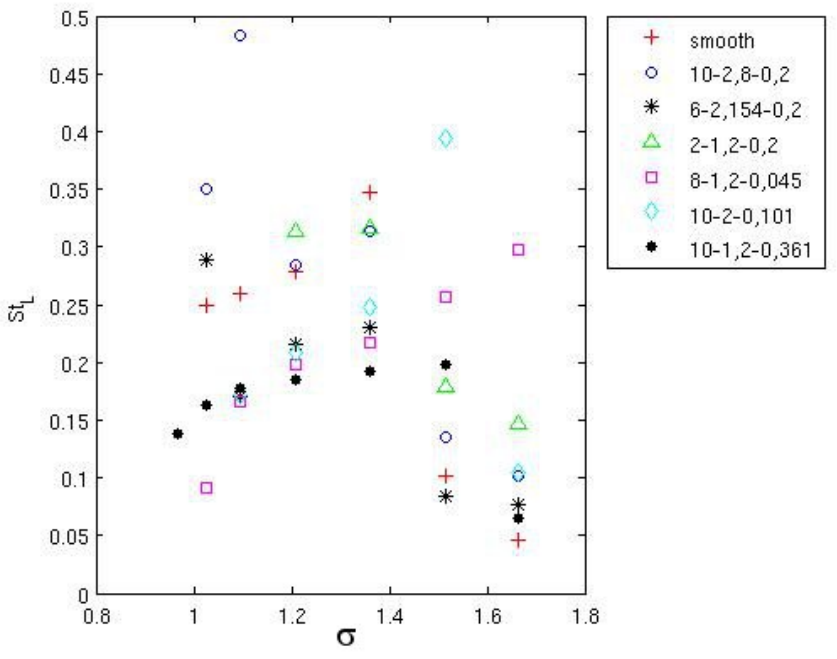

Figure 6. Strouhal number $S t_{L}=\frac{f L}{v_{\text {throat }}}$ according to the cavitation number $\sigma$ for different rugosity shapes of the venturi suction side

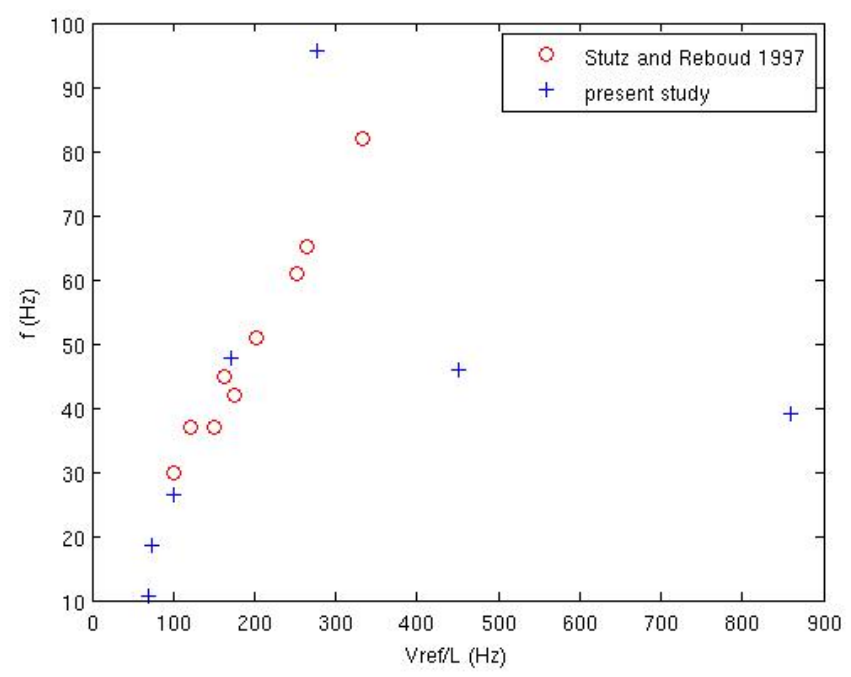

Figure 7. Frequency of cloud cavitation shedding $f$ according to $v_{\text {upstream }} / L$ for different rugosity shapes of the venturi suction side

shown on figure 8 , for the smooth reference case and a grooved case, using grooves with $8 \mathrm{~mm}$ in diameter, $1.2 \mathrm{~mm}$ in depth and a spacing between grooves of $0.045 \mathrm{~mm}$ (this case is called 8-1.2$0.045)$, when the cavitation number is $\sigma=1.1$. We can observe that the mode 1 looks like the mean image in both cases. This is always the shape of the first mode of POD, for an images analysis or others (like velocity or vorticity fields analysis). We can also see that there are differences between the smooth and the grooved sheets on modes 2 and 3 . For the mode 4 , the shape of images seems to be similar but red and blue zones are inversed. These diffrences permit to think that roughness has effect on these modes more particularly. If we can detect that modes witness particular instabilities of the flow, we can know on what part of the flow dynamics the roughness can act. This post-processing is then not a method to explain what happens in the cavity mechanisms 
but a method to discover some avenues of research to explore.

As the most differences between the smooth and the grooved sheets are shown on modes 2 and 3, we can focus our study on these modes to measure the effect of the roughness. Now, if we want to measure the effect of grooves geometry, we can use the figure 9. We can see this time that modes 3 and 4 are different from the grooved sheets $10-2.8-0.2$ and $8-1.2-0.045$, while the mode 2 is more similar. Roughness of these two grooved sheets has different effects on cloud cavitation dynamics because results are different on first POD modes. When we look at the contribution of each mode in the initial images reconstruction (figure 10), using eigenvalues, we can see that for smooth or grooved sheets, contribution of the first modes are similar. We can so validate our comparisons between POD modes of these configurations. Grooves geometry is then a significant parameter in the efficiency of the passive control.

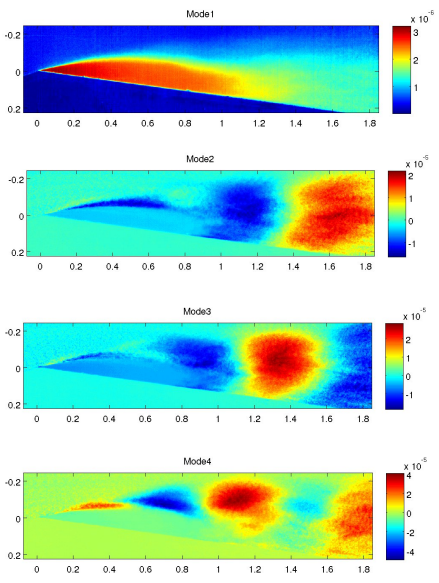

(a)
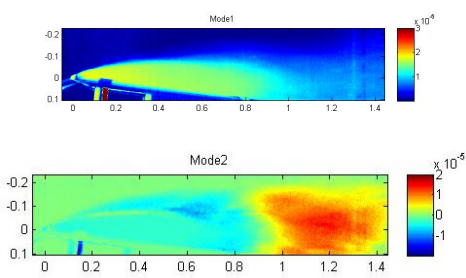

Mode3

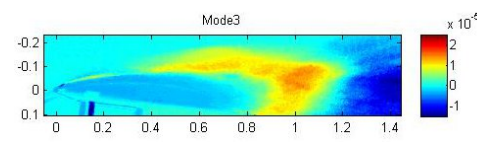

Mode4

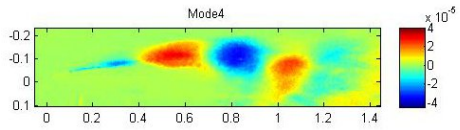

(b)
Figure 8. Modes 1 to 4: (a) for a smooth suction side and (b) for the grooved sheet 8-1.2-0.045 (for $\sigma=1.1$ )
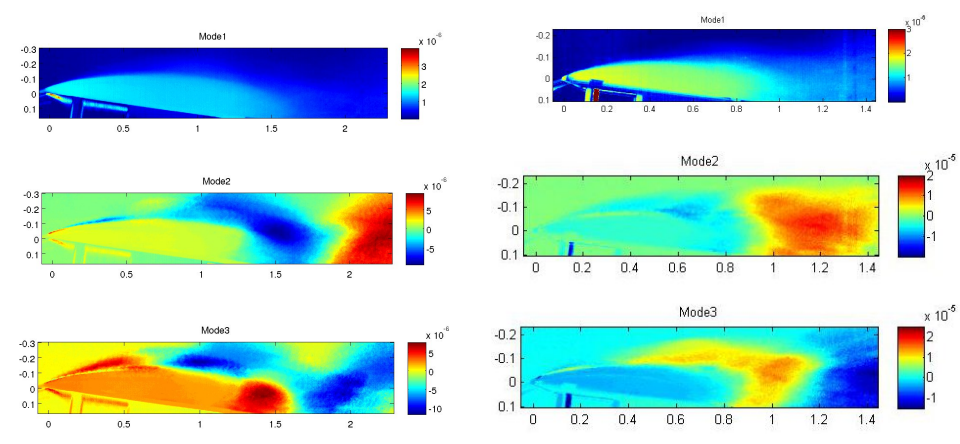

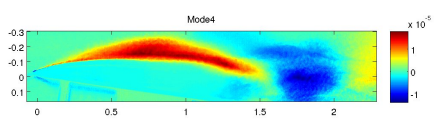

(a)

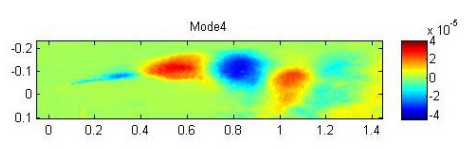

(b)
Figure 9. Modes 1 to 4: (a) for the grooved sheet 10-2.8-0.2 and (b) for the grooved sheet 8-1.2-0.045 (for $\sigma=1.1$ )

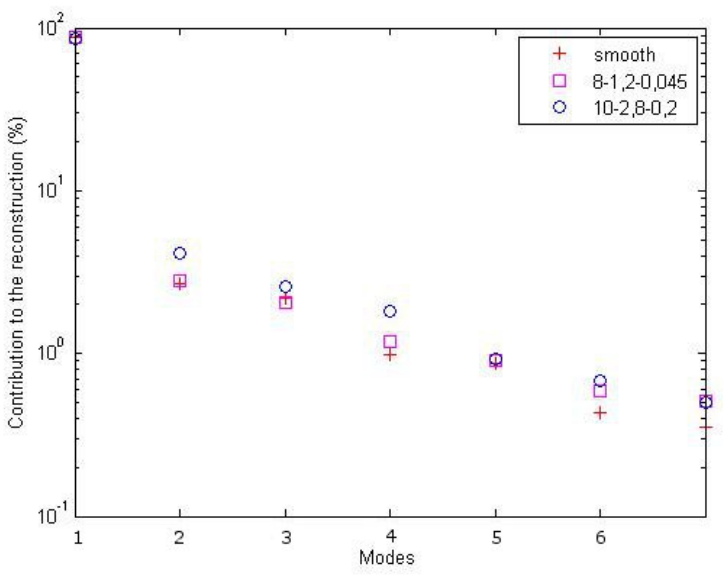

Figure 10. Contribution of each modes to the initial images reconstruction for the smooth case and grooved sheets 8-1.2-0.045 and 102.8-0.2 (for $\sigma=1.1)$

\section{CONCLUSIONS}

A robust post-processing POD technique is used in order to analyze the effect of roughness on the sheet cavitation induced by a venturi type section. Results obtained by visualization measurements permit to give explanations of the effect of grooves and the importance of grooves geometry and spacing. It is difficult in this study to determine what parameters of the grooves geometry are responsible for the different effect obtained with this passive control. If we consider the depth of grooves, this parameter can act on the boundary layer developed on the venturi profile. On the other hand, the spacing between grooves and the diameter of the grooves can modify the three-dimensional structures of the flow which are observed on the figure 11, by recording images of the flow on the top of the test section. This figure is obtained for the smooth reference case, at a cavitation number $\sigma=1.1$. Geometry parameters of the grooves have to be studied in more details but, this study needs a new complex experimental configuration because of the difficulty to make visualizations on the top of grooved sheets.

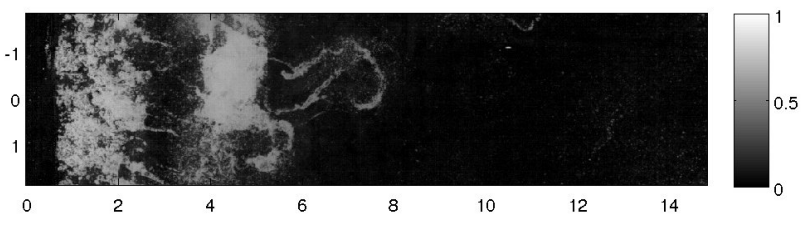

Figure 11. Image recorded on the top of the test section, for the smooth venturi profile, at $\sigma=1.1$ 


\section{REFERENCES}

[1] Knapp, R.T., 1955. "Recent investigation on the mechanics of cavitation and erosion damage". Trans. ASME, 77, pp. 1045-1054.

[2] Stutz, B. and Reboud, J.L., 1997. "Experiments on unsteady cavitation". Experiments in Fluids, 22, pp. 191-198.

[3] Callenaere, M.,Franc, J.P.,Michel, J.M. and Riondet, M., 2001. "The cavitation instability induced by the development of a re-entrant jet". J. Fluid Mech., 444, pp. 223-256.

[4] Dular, M., Bachert, B., Stoffel, B. and Sirok, B., 2004. "Relationship between cavitation structures and cavitation damage". Wear, 257, pp. 1176-1184.

[5] Avellan, F., Dupont, Ph. and Farhat, M., 1991. "Cavitation erosion power". ASME-FED, 16, p. 135140.

[6] Bakir, F., Kouidri, S., Noguera, R. and Rey, R., 2003. "Experimental analysis of an axial inducer influence of the shape of the blade leading edge on the performances in cavitating regime". Journal of Fluids Engineering, Transactions of the ASME, 125(2), pp. 293-301.

[7] Campos-Amezcua, R., Khelladi, S., Bakir, F., MazurCzerwiec, Z., Sarraf, C. and Rey, R., 2003. "Numerical analysis of unsteady cavitating flow in an axial inducer". Proceedings of the Institution of Mechanical Engineers, Part A: Journal of Power and Energy, 224(2), pp. 223-238.

[8] Mejri, I., Bakir, F., Bakir, F. and Belamri, T. "Comparison of computational results obtained from a homogeneous cavitation model with experimental investigations of three inducers".

[9] Arndt, R.E.A., 1981. "Cavitation in fluid machinery and hydraulic structures". Ann. Rev. Fluid Mech., 13, pp. 273328.

[10] Arndt, R.E.A. and Ippen, A.T., 1968. "Rough surface effects on cavitation inception". ASME J. Basic Eng., 90, pp. 249-261.

[11] Coutier-Delgosha, O.,Devillers, J.F., Leriche, M. and Pichon, T., 2005. "Effect of wall roughness on the dynamics of unsteady cavitation". Transactions of the ASME, 127, July, pp. 726-733.

[12] Stutz, B., 2003. "Influence of roughness on the two-phase flow structure of sheet cavitation". Transactions of the ASME, 125, July, pp. 2652-659.

[13] Yonjian, L.,Haosheng, C.,Jiadao, W. and Darong C., 2010. "Effects of grooves on cavitation around the body of revolution". Journal of Fluids Engineering, 132, January.

[14] Holmes, P., L. J., and Berkooz, G., 1996. Turbulence, Coherent Structures, Dunamical Systems and Symmetry. Cambridge Monographs on Mechanics.

[15] Lumley, J.L., 1967. "The structure of inhomogeneous turbulence". In A.M. Yaglom and V.I.Tatarski, editors, Atmospheric Turbulence and Wave Propagation, pp. 166-178. 